\title{
A tale of two vaccines
}

\author{
Fiona Godlee editor in chief
}

The BMJ

Public trust in vaccination programmes is crucial to their success. History tells us that trust is easily undermined by misinformation, but this should not prevent an open and informed debate on the evidence for the effectiveness and safety of vaccines.

Peter Doshi tells a tale of two vaccines rapidly deployed by GSK in 2009 amid fears of a flu pandemic (doi:10.1136/bmj. k3948). There were early internal safety reports showing a higher rate of serious adverse events logged in relation to one of the vaccines, Pandemrix, but these reports were not actively shared with the public, and the vaccine continued to be promoted well into 2010. Cases of suspected serious adverse events, namely incidents of narcolepsy, are currently the subject of legal action against GSK and public health bodies, which is how new documentation has come to light. But why, asks Doshi, was the public not alerted?

In the rapid responses to Doshi's investigation (bmj.com/content/362/bmj.k3948/rapid-responses), GSK and UK and European regulators argue that relevant information was shared, among them at least, and was also made publicly available on their websites. But it took the legal case for GSK's internal safety reports to come to light and a diligent reviewer, Tom Jefferson, to study and compare the rates of adverse events. When he did so, he "just fell off the chair," so striking were the differences between GSK's vaccines. As one solicitor involved in the legal action is quoted as saying, "Any person contemplating taking the Pandemrix vaccine would be likely, if in receipt of this information, not to choose . . vaccination."

Doshi clearly states that the information does not prove causation. But it should have warranted urgent investigation at the time and still deserves this now, he says. He believes this case raises big questions about transparency. When do public health officials have a duty to warn the public over possible harms detected through pharmacovigilance? How much detail should the public be provided with, and who should provide it? Other rapid responders take up this refrain (bmj.com/content/362/bmj.k3948/rapid-responses). Retired paediatrician Allan Cunningham says that in far too many cases the systems for collecting adverse events are simply window dressing to give the appearance of safety monitoring. Retired nurse Wendy Stephen asks where what has happened leaves informed consent, especially as the Montgomery ruling in the UK requires that people be given all the information they need to make a fully informed decision (doi:10.1136/bmj.h1414). Elizabeth Hart quotes a Reuters special report about the problems encountered by researchers who questioned vaccine safety. And on the vexed question of whether raising these concerns does more harm than good, Jefferson concludes that "non response and obfuscation are gifts to those who are ideologically opposed to vaccines and their use."

The spectre of Andrew Wakefield should not deter us from proper scrutiny and openness about vaccine safety. 